\title{
Comparison of clinical and survival characteristics between prostate cancer patients of PSA-based screening and clinical diagnosis in China
}

\author{
Libo Xu ${ }^{1}$, Jinguo Wang ${ }^{2}$, Baofeng Guo ${ }^{3}$, Haixia Zhang ${ }^{4}$, Kaichen Wang ${ }^{3}$, Ding Wang ${ }^{1}$, \\ Chang Dai ${ }^{5}$, Ling Zhang ${ }^{1}$ and Xuejian Zhao ${ }^{1}$ \\ ${ }^{1}$ Department of Pathophysiology, College of Basic Medical Science, Jilin University, Changchun, China \\ ${ }^{2}$ Department of Urology, The First Hospital of Jilin University, Changchun, China \\ ${ }^{3}$ Department of Surgery, China-Japan Union Hospital of Jilin University, Changchun, China \\ ${ }^{4}$ Beijing Chaoyang District Center for Disease Control and Prevention, Beijing, China \\ ${ }^{5}$ Department of Ophthalmology, Second Hospital of Jilin University, Changchun, China \\ Correspondence to: Ling Zhang, email: zhangling3@jlu.edu.cn \\ keywords: prostate cancer, PSA-based mass screening, prostate-cancer specific mortality, overall survival, metastases \\ Received: May 19, $2017 \quad$ Accepted: June 29, $2017 \quad$ Published: September 08, 2017 \\ Copyright: $\mathrm{Xu}$ et al. This is an open-access article distributed under the terms of the Creative Commons Attribution License 3.0 \\ (CC BY 3.0), which permits unrestricted use, distribution, and reproduction in any medium, provided the original author and source \\ are credited.
}

\section{ABSTRACT}

Prostate-specific antigen (PSA)-based mass screening remains the most controversial topic in prostate cancer. PSA-based mass screening has not been widely used in China yet. The aim of our study was to evaluate the effect of the PSA-based screening in China. The cohort consisted of 1,012 prostate cancer patients. Data were retrospectively collected and clinical characteristics of the cohorts were investigated. Survival was analyzed for prostatic carcinoma of both PSA screened and clinically diagnosed patients according to clinical characteristics and the National Comprehensive Cancer Network (NCCN) risk classification. Cox Proportional Hazards Model analysis was done for risk predictor identification. The median age was $\mathbf{7 1}$ years old. Five-year overall and prostate-cancer-specific survival in prostatic adenocarcinoma patients were $77.52 \%$ and $79.65 \%$; 10 -year survivals were $\mathbf{6 2 . 5 7 \%}$ and $\mathbf{6 8 . 6 0 \%}$, respectively. Survival was significantly poorer in patients with metastases and non-curative management. T staging and Gleason score by NCCN classification effectively stratified prostatic adenocarcinoma patients into different risk groups. $T$ staging was a significant predictor of survival by COX Proportional Hazard Model. PSA screened patients had a significantly higher percentage diagnosed in early stage. PSA screened prostatic adenocarcinoma patients had a better prognosis in both overall and prostate cancer-specific survivals. This Chinese cohort had a lower overall and prostate cancer survival rate than it is reported in western countries. The incidence of early-stage prostate cancer found in PSA-based mass screening was high and there were significant differences in both overall and prostate cancer-specific survival between the PSA-screened and clinically diagnosed patients.

\section{INTRODUCTION}

Prostate cancer is one of the most common malignancies among males, especially in developed countries [1]. It is estimated that over 160,000 new cases of prostate cancer will be diagnosed in 2017 in the United States, accounting for 19\% of all cancer cases [2]. In European countries too, prostate cancer is the most common non-skin cancer in men over 70 years old [3]. With the development of novel diagnostic and therapeutic 
technologies in the past decades, a drop of more than $25 \%$ in cancer death rates was witnessed since early 1990s in the United States [4]. Reduction in prostate cancer mortality during last decades was also reported in European counties with long term follow-up [5].

By comparison, Asian countries including China were reported as having a relatively low rate [4]. However a sharp increase in prostate cancer incidence in China was recorded in the past few decades, probably due to a combination of factors including ageing and dietary and lifestyle changes. Based on age-standardized rate per 100,000 analysis, an epidemiological study of Cancer Institute of Shanghai reported an incidence increase from 0.48 in 1960 s to 2.41 in $1990 \mathrm{~s}$. In recent years another worldwide study showed an elevated incidence rate in China from 4.48 to 13.33 and an over 5-fold mortality increase as well between 2009 and 2013 [1,5].

Incidence rates from 1975 through 2013 in the United States showed a dramatic increase during late 1980s and early 1990s and then a marked drop from 1992 to 1995 . Thereafter the incidence declined annually and showed a sharp reduction of more than $10 \%$ in particular from 2010 to 2013 [6, 7]. The dramatic shifts were considered a reflection of changing patterns of prostate-specific antigen (PSA) mass screening, which was recommended initially by the American Cancer Society (ACS) and the American Urological Association (AUA) from the late 1980s [2, 7]. However, the 2008 and 2012 US Preventive Services Task Force (USPSTF) guidelines discouraged routine PSA screening because of concerns about the uncertain balance between the benefits of screening for early detection and the harmful effects of overdiagnosis and the resultant overtreatment $[8,9]$. PSA-based mass screening is therefore one of the most controversial topics in prostate cancer diagnosis.

Because of the geographical differences in incidence of prostate cancer, there has been less epidemiological research in Asian countries. PSA-based mass screening has not been widely used in China yet. The question whether PSA-based mass screening can reduce mortality in Chinese prostate cancer patients and how to balance the uncertain benefits and risks of screening remains to be determined. Hence, to evaluate the effect of PSA-based mass screening in China, as early as 1996, the Center of Diagnosis, Treatment and Research of Prostate Disease of Jilin University launched a PSA-based mass screening program for prostate cancer in a Chinese cohort in Changchun, China, in cooperation with Japan International Cooperation Agency (JICA).

The present study investigated the clinical characteristics and survival of Chinese patients to uncover the epidemiological features of prostate cancer in China with the hope of identifying reliable diagnostic and prognostic risk factors. It also compares prostate cancer between patients detected by PSA-based mass screening and those identified by clinical diagnosis, to evaluate the effect of PSA-based mass screening. We hoped to aid clinicians on better selection in management options to enhance treatment efficacy as well as guide health authorities for policy-making on prostate cancer in China.

\section{RESULTS}

Of the 1,012 patients in the study, 984 men were diagnosed as having prostatic adenocarcinoma and 28 as having other types of prostate cancer, including squamous cell carcinoma, prostatic sarcomas and transitional cell carcinomas. The median age of the whole cohort was 71 years.

\section{Clinical characteristics of the whole cohort}

The distribution of clinical characteristics was analyzed and is shown in Table 1 based on median age. The median PSA level was significant higher in the group of median Age $>71$ years (median 25.25 and $29.3 \mathrm{ng} /$ $\mathrm{mL}$, respectively, $P=0.0056$ ). Also, there were significant differences in the year of diagnosis $(P<0.0001)$, T staging $(P=0.0002)$, management approach $(P<0.0001)$ as well as follow-up time $(P<0.0001)$.

Given that most cancer deaths were attributable to the metastatic prostate cancer, the distribution of clinical characteristics based on metastatic status at diagnosis was further analyzed and is shown in Table 2. Men with metastases had a significantly higher median PSA level than those without metastases $(70.05 \mathrm{ng} / \mathrm{mL}$ and 15.70 $\mathrm{ng} / \mathrm{mL}$, respectively, $P<0.0001)$. Also, differences in $\mathrm{T}$ staging, Gleason score and follow-up time were significant between the two groups $(P<0.0001)$.

\section{PSA-based mass screening and clinically diagnosed prostate cancer patients}

\section{Overall survival and prostate cancer-specific mortality}

Survival is one of the most important indicators for PSA-based mass screening evaluation. Hence, the overall and prostate cancer-specific survival in both PSA-based mass screening and clinically diagnosed prostate cancer patients as a whole was analyzed firstly in this study. To reduce the heterogeneity, prostate cancer in special types were excluded and therefore, 984 men with prostatic adenocarcinoma were included for survival analysis.

\section{(i) Basic characteristics and survival}

Kaplan-Meier plots for overall and prostate cancerspecific survival of patients with prostatic adenocarcinoma are shown in Figure 1a. Five-year overall and prostate cancer-specific survivals were $77.52 \%$ and $79.65 \%$ respectively. The 10 -year survivals were $62.57 \%$ and $68.60 \%$ respectively. Statistical significance was found between overall and prostate cancer-specific survivals $(P=0.0409)$. Subsequently, the overall survival and 
Table 1: Patient clinical characteristics based on median age

\begin{tabular}{|c|c|c|c|c|c|c|}
\hline $\begin{array}{l}\text { Clinial } \\
\text { characteristic }\end{array}$ & $\begin{array}{c}\text { Whole cohort } \\
\qquad \mathbf{N}>\mathbf{1 0 1 2}\end{array}$ & & $\begin{array}{c}\text { Age }<=71 \\
\mathbf{N}>529\end{array}$ & & $\begin{array}{c}\text { Age }>71 \\
N>479\end{array}$ & \\
\hline Median age, year & 71 & & 65 & & 76 & \\
\hline \multicolumn{7}{|l|}{ Year of diagnosis } \\
\hline $1980-1990$ & 68 & $6.7 \%$ & 52 & $9.8 \%$ & 16 & $3.3 \%$ \\
\hline 1991-2000 & 268 & $26.6 \%$ & 182 & $34.4 \%$ & 86 & $18.0 \%$ \\
\hline 2001-2012 & 672 & $66.7 \%$ & 295 & $55.8 \%$ & 377 & $78.7 \%$ \\
\hline
\end{tabular}

\section{Clinical staging}

\section{T staging*}

$\mathrm{T} 1$

$\mathrm{T} 2$

T3

$\mathrm{T} 4$

Missing data

N staging

$\begin{array}{ll}\text { N0 } & 531 \\ \text { N1,2 } & 3 \\ \text { Nx } & 447\end{array}$

\section{M staging*}

M0
Mx

Median

PSA(IQR), ng/mL

Missing data

\section{Gleason score*}

$<=6$

7

7

8

9

10

Missing data
531

30

447

55

395

120

185

253

$44.3 \%$

$5.5 \%$

$39.2 \%$

$11.9 \%$

$18.4 \%$

$25.1 \%$

108

$52.7 \%$

324

22

183

31

192

74

124

108

$20.4 \%$

$5.9 \%$

$36.3 \%$

$14.0 \%$

$23.4 \%$

$61.2 \%$

$4.2 \%$

$34.6 \%$

$34.6 \%$

518

244

246

26.7

357

$35.4 \%$

$51.4 \%$

296

133

$24.2 \%$

100

(0-1000) $\quad 25.25$

(0-241.2)

239

$45.2 \%$

$25.1 \%$

$18.9 \%$

24

203

46

61

145

222

111

146

29.3

(0.1-1000)

$\begin{array}{ccc}204 & 20.2 \% & 104 \\ 176 & 17.5 \% & 77 \\ 117 & 11.6 \% & 46 \\ 117 & 11.6 \% & 62 \\ 24 & 2.4 \% & 12 \\ 370 & 36.7 \% & 228\end{array}$

\begin{abstract}
$19.7 \%$
$14.6 \%$

$8.7 \%$

$11.7 \%$

$2.3 \%$
\end{abstract}

$43.1 \%$
118

100

99

71

55

12

142
N0 vs N1,2, $P=0.1795$

M0 vs M1, $P=0.4803$

$P=0.0056$

$P=0.1599$

$P<0.0001$

$$
P=0.0002
$$

$5.0 \%$

$42.4 \%$

$9.6 \%$

$12.7 \%$

$30.3 \%$

$43.2 \%$

$1.7 \%$

$55.1 \%$

$46.3 \%$

$23.2 \%$

$30.5 \%$

$24.6 \%$

$20.9 \%$

$20.7 \%$

$14.8 \%$

$11.5 \%$

$2.5 \%$

$29.6 \%$

(Continued) 


\begin{tabular}{|c|c|c|c|c|c|c|c|}
\hline $\begin{array}{l}\text { Clinial } \\
\text { characteristic }\end{array}$ & $\begin{array}{l}\text { Whole cohort } \\
\quad N>1012\end{array}$ & & $\begin{array}{c}\text { Age }<=71 \\
N>529\end{array}$ & & $\begin{array}{c}\text { Age }>71 \\
N>479\end{array}$ & & P value \\
\hline $\begin{array}{l}\text { No. of all-cause } \\
\text { death, no. }(\%)\end{array}$ & 269 & $26.7 \%$ & 144 & $27.2 \%$ & 125 & $26.1 \%$ & \\
\hline $\begin{array}{l}\text { No.of cancer } \\
\text { specific death, no. } \\
(\%)\end{array}$ & 225 & $22.3 \%$ & 127 & $24.0 \%$ & 98 & $20.5 \%$ & \\
\hline $\begin{array}{l}\text { Management } \\
\text { approach }\end{array}$ & & & & & & & $P<0.0001$ \\
\hline Curative & 55 & $5.5 \%$ & 46 & $8.7 \%$ & 9 & $1.9 \%$ & \\
\hline Non-curative & 953 & $94.5 \%$ & 483 & $91.3 \%$ & 470 & $98.1 \%$ & \\
\hline $\begin{array}{l}\text { Median follow-up } \\
\text { time, year }\end{array}$ & 5 & $(0.08-23)$ & 6 & $(0.08-23)$ & 4 & $(0.1-23)$ & $P<0.0001$ \\
\hline
\end{tabular}

$\mathrm{IQR}$, interquartile range.

*Percentages may not add up to 100 due to rounding.

prostate cancer-specific survival was compared between different category groups based on median age, metastatic status and management approach. There was no significant difference between patients based on median age (overall survival, Figure $1 \mathrm{~b}, P=0.1691$; prostate cancer-specific mortality, Figure $1 \mathrm{c}, P=0.8835$ ). However, there were significant differences in survival regarding to metastatic status (overall survival, Figure 1d, $P=0.0004$; prostate cancer-specific mortality, Figure 1e, $P<0.0001)$. Also curative management appeared to significantly improve the survival of patients in comparison to non-curative management (overall survival, Figure 1f, $P=0.0010$; prostate cancer-specific mortality, Figure 1g, $P=0.0038$ ).

(ii) NCCN classification and survival

The NCCN classification categorizes prostate cancer into low, intermediate and high risks based on PSA value, $\mathrm{T}$ stage and Gleason score. The intermediate risk group is defined as including at least one of the characteristics: PSA 10-20 ng/mL, American Joint Committee on Cancer tumor (T) category T2b-T2c or Gleason 7 [11]. Accordingly, we compared the overall survival and prostate cancer-specific mortality among different PSA, T staging and Gleason score subgroups individually and also among different NCCN risk categories.

For survival comparison based on PSA levels, 639 patients with defined PSA level records were classified into three groups: $\mathrm{PSA}<10,10 \leq \mathrm{PSA} \leq 20$ and $\mathrm{PSA}>20$. Five-year overall survivals were $88.56 \%, 92.69 \%$ and $81.02 \%$ respectively and 10 -year survivals were $74.65 \%$, $78.14 \%$ and $54.93 \%$ respectively (Figure $2 \mathrm{a}, P=0.0044$ ). Five-year prostate cancer-specific survivals were $92.59 \%$,
$96.36 \%$ and $82.16 \%$ respectively and 10 -year survivals were $87.90 \%, 96.36 \%$ and $62.19 \%$ respectively (Figure 2b, $P<0.0001$ ).

$\mathrm{T}$ staging and Gleason score appeared to be better able to reduce the heterogeneity with regard to both overall survival and prostate cancer specific survivals. For $\mathrm{T}$ staging, 734 patients were subcategorized into three groups of T1-T2a, T2b-T2c and T3-T4. Five-year overall survivals were $89.10 \%, 78.53 \%$ and $61.19 \%$ respectively and 10 -year survivals were $80.89 \%$, $54.99 \%$ and $52.81 \%$ respectively (Figure $2 \mathrm{c}, P<0.0001$ ). The five-year prostate cancer-specific survivals were $95.65 \%, 80.50 \%$ and $62.99 \%$, respectively and 10 -year survivals were $89.81 \%, 65.51 \%$ and $54.36 \%$ respectively (Figure $2 \mathrm{~d}, P<0.0001$ ). In 631 patients with Gleason $\leq 6$, Gleason 7 and Gleason $\geq 8$, five-year overall survivals were $84.15 \%, 83.49 \%$ and $68.32 \%$ respectively and 10 -year survivals were $76.16 \%, 53.88 \%$ and $51.69 \%$ respectively (Figure 2e, $P=0.0004$ ). Five-year prostate cancer-specific survivals were $87.24 \%, 88.33 \%$ and $69.42 \%$, respectively and 10-year survivals were $84.64 \%, 67.35 \%$ and $55.08 \%$, respectively (Figure $2 \mathrm{f}$, $P<0.0001)$.

Subsequently, 803 patients were subcategorized as low, intermediate and high risk, respectively. As analyzed, five-year survivals were $95.65 \%, 91.29 \%$ and $72.81 \%$ respectively and 10 -year survivals were $95.65 \%, 75.53 \%$ and $56.84 \%$ respectively (Figure $2 \mathrm{~g}, P=0.0019$ ). Five-year prostate cancer-specific survivals were $95.65 \%, 98.88 \%$ and $74.23 \%$ respectively and 10-year survivals were $95.65 \%, 98.88 \%$ and $60.93 \%$, respectively (Figure $2 \mathrm{~h}$, $P<0.0001)$. 
Table 2: Patient clinical characteristics based on metastases status

\begin{tabular}{|c|c|c|c|c|c|c|c|}
\hline $\begin{array}{l}\text { Clinial } \\
\text { characteristic }\end{array}$ & $\begin{array}{l}\text { Whole } \\
\text { N>763 }\end{array}$ & & $\begin{array}{c}\text { Non- } \\
\text { metastases } \\
\mathrm{N}>\mathbf{5 1 9}\end{array}$ & & $\begin{array}{c}\text { Metastases } \\
\mathrm{N}>\mathbf{2 4 4}\end{array}$ & & P value \\
\hline $\begin{array}{l}\text { Median age at } \\
\text { diagnosis, year }\end{array}$ & 70 & & 70 & & 71 & & $P=0.1998$ \\
\hline Missing data & 239 & & & & & & \\
\hline Year of diagnosis & & & & & & & $P=0.0008$ \\
\hline 1980-1990 & 68 & $8.9 \%$ & 54 & $10.4 \%$ & 14 & $5.7 \%$ & \\
\hline $1991-2000$ & 265 & $34.7 \%$ & 196 & $37.8 \%$ & 69 & $28.3 \%$ & \\
\hline 2001-2012 & 430 & $56.4 \%$ & 269 & $51.8 \%$ & 161 & $66.0 \%$ & \\
\hline \multicolumn{8}{|l|}{ Clinical staging } \\
\hline T staging & & & & & & & $P<0.0001$ \\
\hline $\mathrm{T} 1$ & 55 & $7.2 \%$ & 55 & $10.6 \%$ & 0 & $0.0 \%$ & \\
\hline $\mathrm{T} 2$ & 389 & $51.0 \%$ & 261 & $50.3 \%$ & 128 & $52.5 \%$ & \\
\hline $\mathrm{T} 3$ & 116 & $15.2 \%$ & 94 & $18.1 \%$ & 22 & $9.0 \%$ & \\
\hline $\mathrm{T} 4$ & 185 & $24.2 \%$ & 91 & $17.5 \%$ & 94 & $38.5 \%$ & \\
\hline Missing data & 18 & $2.4 \%$ & 18 & $3.5 \%$ & 0 & $0.0 \%$ & \\
\hline $\begin{array}{l}\text { Median PSA(IQR), } \\
\text { ng/mL }\end{array}$ & 25.4 & $(0-345)$ & 15.70 & $(0-345)$ & 70.05 & $(0-241.2)$ & $P<0.0001$ \\
\hline Missing data & 320 & $41.9 \%$ & 250 & $48.2 \%$ & 70 & $28.7 \%$ & \\
\hline Gleason score & & & & & & & $P<0.0001$ \\
\hline$<=6$ & 182 & $23.9 \%$ & 146 & $28.1 \%$ & 36 & $14.8 \%$ & \\
\hline 7 & 143 & $18.7 \%$ & 92 & $17.7 \%$ & 51 & $20.9 \%$ & \\
\hline 8 & 96 & $12.6 \%$ & 48 & $9.2 \%$ & 48 & $19.7 \%$ & \\
\hline 9 & 97 & $12.7 \%$ & 54 & $10.4 \%$ & 43 & $17.6 \%$ & \\
\hline 10 & 21 & $2.8 \%$ & 16 & $3.1 \%$ & 5 & $2.0 \%$ & \\
\hline Missing data & 224 & $29.4 \%$ & 163 & $31.4 \%$ & 61 & $25.0 \%$ & \\
\hline $\begin{array}{l}\text { Management } \\
\text { approach }\end{array}$ & & & & & & & $P=0.2452$ \\
\hline Curative & 49 & $6.4 \%$ & 37 & $7.1 \%$ & 12 & $4.9 \%$ & \\
\hline Non-curative & 714 & $93.6 \%$ & 482 & $92.9 \%$ & 232 & $95.1 \%$ & \\
\hline $\begin{array}{l}\text { No.of all-cause } \\
\text { death, no.(\%) }\end{array}$ & 264 & $34.6 \%$ & 166 & $32.0 \%$ & 98 & $40.2 \%$ & \\
\hline $\begin{array}{l}\text { No.of prostate } \\
\text { cancer specific } \\
\text { death, no. }(\%)\end{array}$ & 221 & $29.0 \%$ & 128 & $24.7 \%$ & 93 & $38.1 \%$ & \\
\hline $\begin{array}{l}\text { Median follow-up } \\
\text { time, year }\end{array}$ & 6 & $(0.08-23)$ & 6 & $(0.08-23)$ & 5 & $(0.41-16)$ & $P<0.0001$ \\
\hline
\end{tabular}

IQR, interquartile range.

*Percentages may not add up to 100 due to rounding. 
(iii) Cox Proportional Hazards Model and survival

After a median follow-up of five years (IQR, 0.0823 years) for the whole cohort, there were 269 deaths $(26.58 \%)$ in total, 225 of which were prostate cancerspecific deaths (83.64\%). Cox Proportional Harzard Model analysis for overall survival and prostate cancerspecific mortality of the whole cohort is shown in Table 3. Eight co-facters, including age at the time of diagnosis, year of diagnosis, PSA level, TNM staging, Gleason score and management approach, were analyzed with the model. $\mathrm{T}$ staging and year of diagnosis were significant predictors in overall survival ( $P=0.008$ and $P=0.030$, respectively) whereas for prostate cancer-specific death, $\mathrm{T}$ staging was the only significant predictor of survival $(P=0.044)$.

Cox Proportional Hazard Model analysis was performed for patients with prostatic adenocarcinoma (Table 4). Among 984 men with prostatic adenocarcinoma, there were 261 all-cause deaths in total and 217 deaths caused by prostate cancer $(83.14 \%)$. Similarly, T staging and year of diagnosis were significant predictors of overall survival ( $P=0.006$ and $P=0.040$, respectively). T staging was the only significant predictor of prostate-cancerspcific survival $(P=0.031)$.

\section{Clinical and survival characteristics in PSA- based mass screening and clinically diagnosed prostate cancer patients}

Through the survival analysis, it was found that the overall and prostate cancer-specific survival was high in the Chinese cohort in comparison to it is in the western countries where PSA-based mass screening have been widely used for decades. In order to figure out whether PSAbased mass screening is contribute to mortality reduction in prostate cancer, we further compared the clinical and survival characteristics between PSA-based mass screening and clinically diagnosed prostate cancer patients.

Based on PSA-based mass screening, 383 men were diagnosed as having prostate cancer. Of these, 358 men had prostatic adenocarcinoma. 259 of them had biopsies and were diagnosed immediately and 99 men refused biopsies at first and were diagnosed years later when their PSA levels were very high. Therefore, in this study, to reduce discrepancies, these 99 men were subcategorized into another group as "PSA screened with later diagnosis", whereas the other 259 patients were subcategorized as "PSA screened" patients. Clinical characteristics and
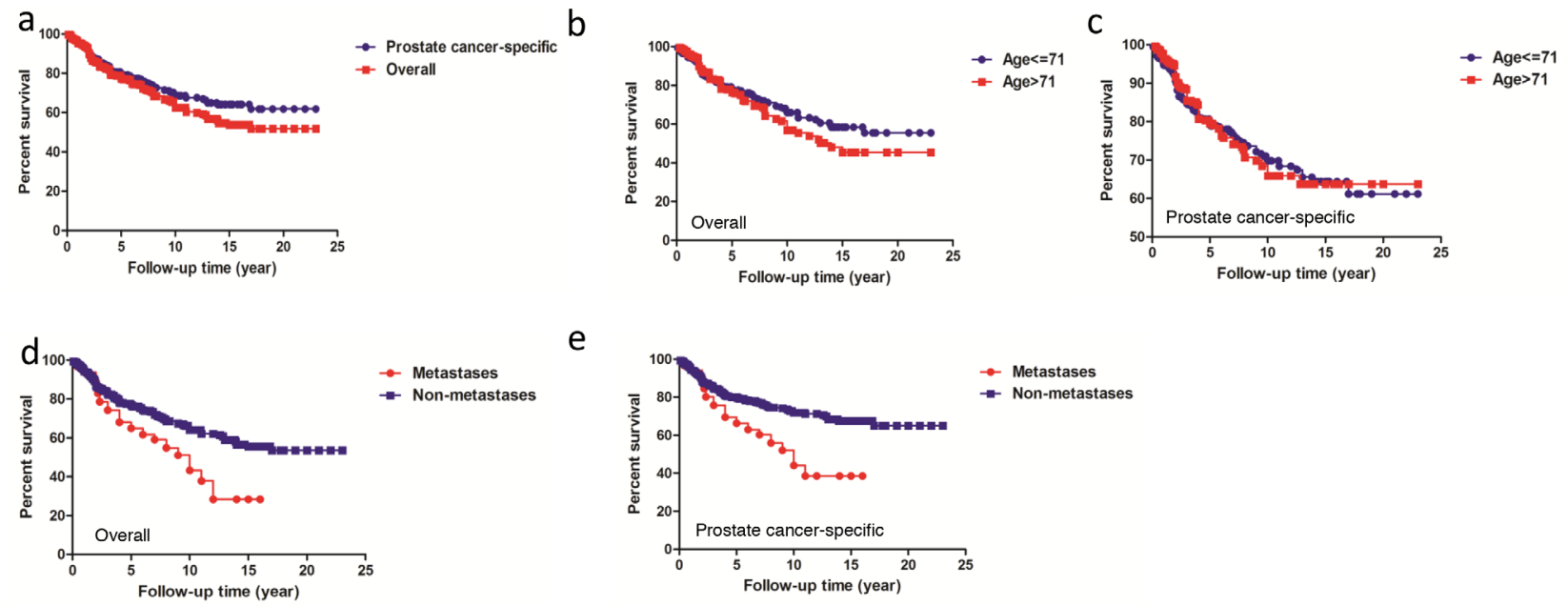

e
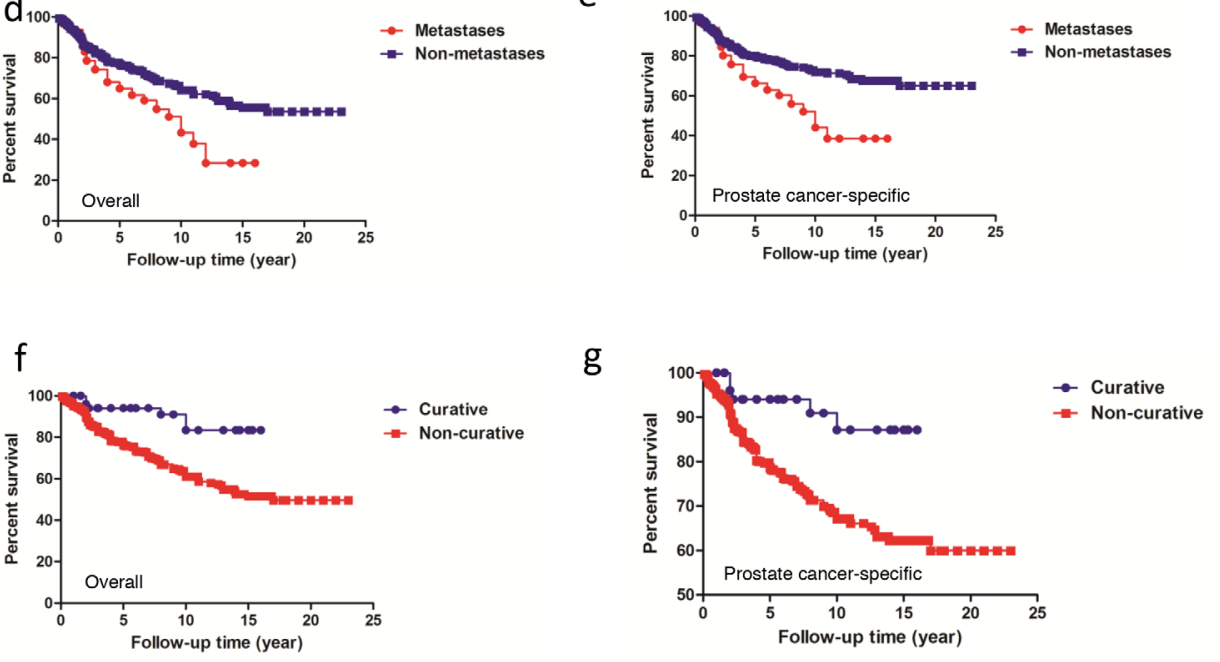

Figure 1: Overall and prostate cancer-specific survivals based on median age, metastatic status and management approach. (a) Comparison of overall and prostate cancer-specific survival for the whole cohort, $P=0.0409$. (b, c) Overall and prostate cancer-specific survival comparison for men between age 71 or less and age $>71$. (d, e) Overall and prostate cancer-specific survival comparision for men with/without metastases. (f, g) Overall and prostate cancer-specific survival comparision based on management approach. 
survival were compared in three groups: 259 PSA screened patients, 99 PSA screened patients with later diagnosis, and 626 clinically diagnosed prostatic adenocarcinoma patients.

\section{(i) Clinical characteristics}

The clinical characteristics comparison is shown in Table 5. The distribution of TNM staging, Gleason score, median age, and follow-up time, as well as median PSA level were significantly different among PSA screened, PSA screened with later diagnosis, and the clinically diagnosed groups $(P<0.0001)$. Also, there were significant differences in management approach $(P=0.0049)$.

To understand the detailed differences in distribution of clinical staging, Gleason score and management approach, we further compared the distribution within the subgroups of T1-2 versus T3-4; N0 versus N1-2, M0 versus $\mathrm{M} 1$, and curative versus non-curative management, as well as Gleason $\leq 6$, Gleason 7 and Gleason $\geq 8$.

For $\mathrm{T}$ staging, statistical significances were indicated among the subgroups (Figure $3 \mathrm{a}, P<0.0001$ ) and a

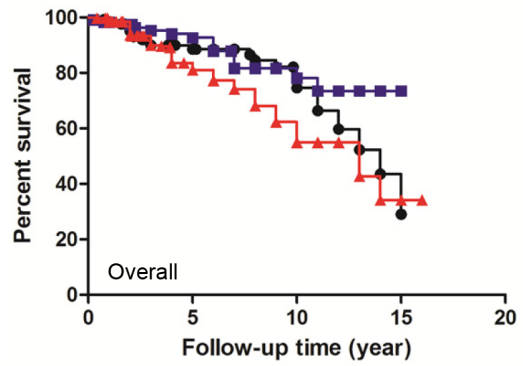

C

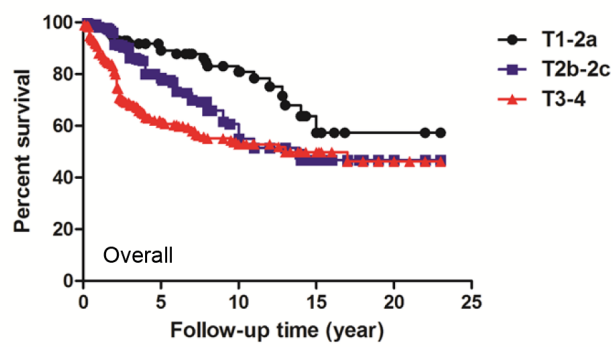

e

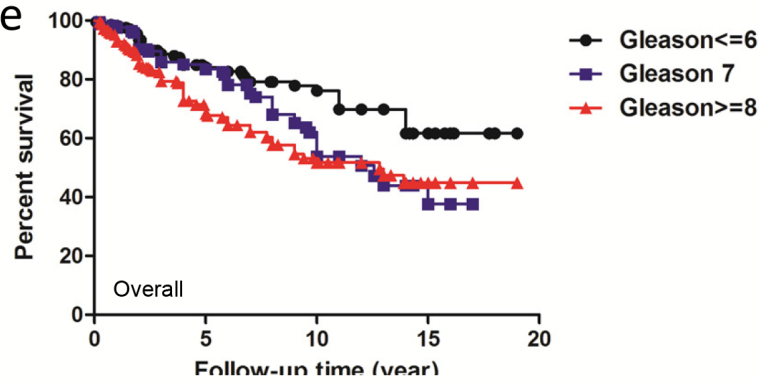

$\mathrm{g}$

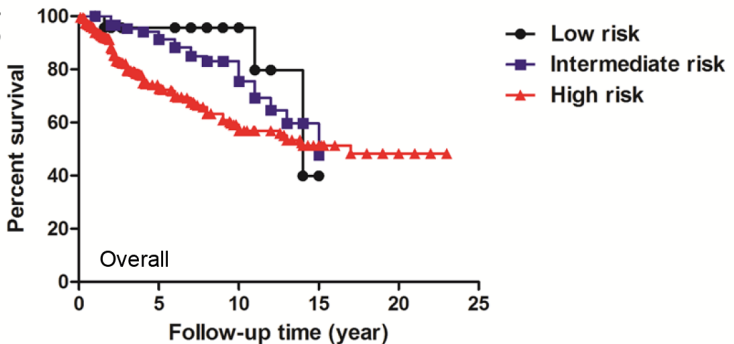

b

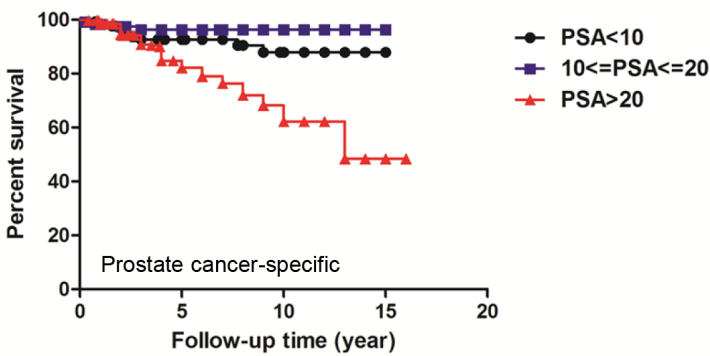

d
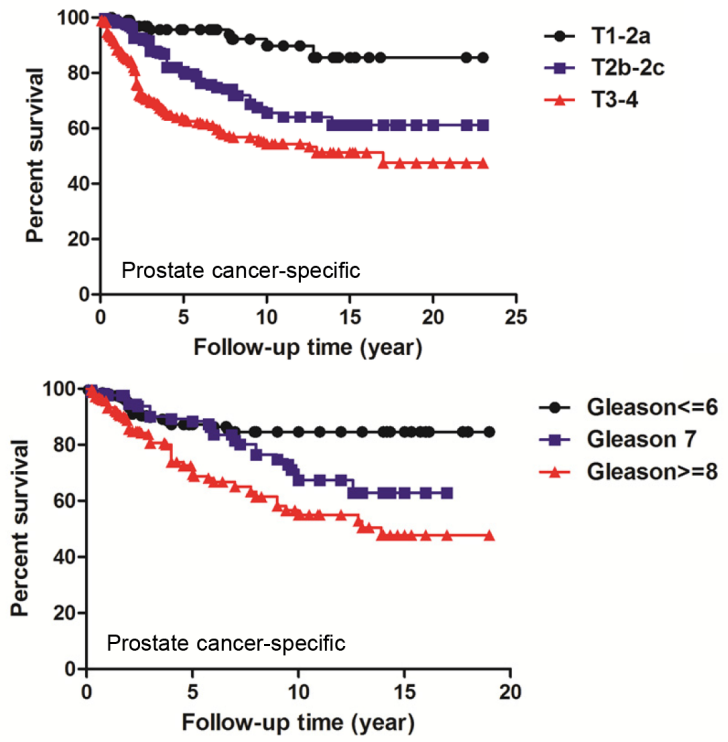

$\mathrm{h}$

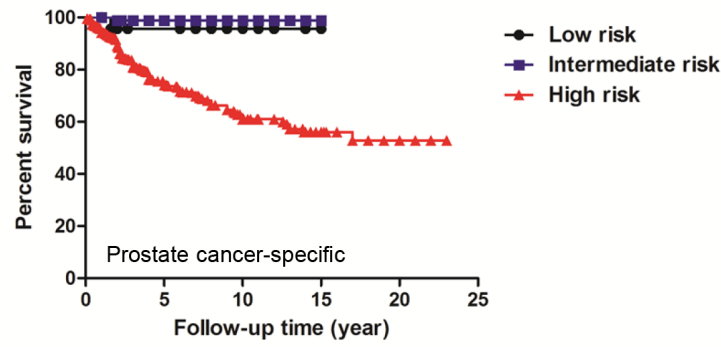

Figure 2: Overall survival and prostate cancer specific-survival according to each NCCN classification related factor PSA, T stage and Gleason score as well as NCCN risk categories. (a, b) Overall and prostate cancer-specific survival comparison among patients with PSA $<10,10 \leq \mathrm{PSA} \leq 20$ and PSA $>20$. (c, d) Overall and prostate cancer-specific survival comparison among subcategories of patients with T1-T2a, T2b-T2c and T3-T4. (e, f) Overall and prostate cancer-specific survival comparison among patients with Gleason $\leq 6$, Gleason 7 and Gleason $\geq 8$. $(\mathbf{g}, \mathbf{h})$ Overall and prostate cancer-specific survival comparision based on the NCCN classification. 
Table 3: Cox proportional hazard model for the whole cohort

\begin{tabular}{|c|c|c|c|c|c|c|}
\hline \multirow{2}{*}{$\begin{array}{l}\text { Clinical } \\
\text { characteristics }\end{array}$} & \multicolumn{3}{|c|}{ Overall survival } & \multicolumn{3}{|c|}{ Prostate cancer-specific survival } \\
\hline & HR & $95 \% \mathrm{CI}$ & $P$ & HR & $95 \% \mathrm{CI}$ & $\boldsymbol{P}$ \\
\hline $\begin{array}{l}\text { Age at the time } \\
\text { of diagnosis, } \\
\text { year }\end{array}$ & 1.016 & $0.98-1.053$ & 0.401 & 0.999 & $0.951-1.05$ & 0.976 \\
\hline $\begin{array}{l}\text { Year of } \\
\text { diagnosis }\end{array}$ & 1.114 & $1.01-1.228$ & 0.030 & 1.06 & $0.927-1.211$ & 0.395 \\
\hline PSA, ng/mL & 0.996 & $0.984-1.008$ & 0.530 & 1.003 & $0.989-1.016$ & 0.702 \\
\hline T staging & 1.897 & $1.179-3.054$ & 0.008 & 1.87 & $1.018-3.436$ & 0.044 \\
\hline $\mathrm{N}$ staging & 0.255 & $0.029-2.238$ & 0.218 & 0.767 & $0.083-7.062$ & 0.815 \\
\hline M staging & 0.686 & $0.231-2.037$ & 0.497 & 0.396 & $0.087-1.802$ & 0.231 \\
\hline Gleason score & 0.966 & $0.862-1.082$ & 0.546 & 0.924 & $0.796-1.072$ & 0.295 \\
\hline $\begin{array}{l}\text { Management } \\
\text { approach }\end{array}$ & 0.509 & $0.173-1.501$ & 0.221 & 1.096 & $0.296-4.064$ & 0.891 \\
\hline
\end{tabular}

95\% CI, 95\% confidence interval; HR, hazard ratio.

Table 4: Cox proportional hazard model for prostatic adenocarcinoma patients

\begin{tabular}{|c|c|c|c|c|c|c|}
\hline \multirow{2}{*}{$\begin{array}{l}\text { Clinical } \\
\text { characteristics }\end{array}$} & \multicolumn{3}{|c|}{ Overall survival } & \multicolumn{3}{|c|}{ Prostate cancer-specific survival } \\
\hline & HR & $95 \%$ CI & $\boldsymbol{P}$ & HR & $95 \% \mathrm{CI}$ & $\boldsymbol{P}$ \\
\hline $\begin{array}{l}\text { Age at the time } \\
\text { of diagnosis, } \\
\text { year }\end{array}$ & 1.015 & $0.977-1.053$ & 0.445 & 0.999 & $0.948-1.053$ & 0.974 \\
\hline $\begin{array}{l}\text { Year of } \\
\text { diagnosis }\end{array}$ & 1.11 & $1.005-1.226$ & 0.040 & 1.047 & $0.913-1.201$ & 0.51 \\
\hline PSA, ng/mL & 0.996 & 0.984-1.009 & 0.564 & 1.004 & $0.99-1.018$ & 0.571 \\
\hline T staging & 2.027 & $1.226-3.349$ & 0.006 & 2.068 & $1.067-4.01$ & 0.031 \\
\hline $\mathrm{N}$ staging & 0.221 & $0.025-1.956$ & 0.175 & 0.67 & $0.07-6.441$ & 0.729 \\
\hline M staging & 0.649 & $0.214-1.968$ & 0.445 & 0.35 & $0.071-1.719$ & 0.196 \\
\hline Gleason score & 1 & $0.883-1.133$ & 0.998 & 0.987 & $0.838-1.162$ & 0.872 \\
\hline $\begin{array}{l}\text { Management } \\
\text { approach }\end{array}$ & 0.366 & $0.107-1.244$ & 0.107 & 0.727 & $0.155-3.403$ & 0.686 \\
\hline
\end{tabular}

95\% CI, 95\% confidence interval; HR, hazard ratio.

PSA-screened patients had a higher percentage in T1-2 distribution (96\%) in comparison to PSA-screened with later diagnosis $(81 \%)$ and clinically diagnosed patients (29\%). As to N staging, there was a significant difference between PSA screened and clinically diagnosed patients (Figure $3 \mathrm{~b}, P=0.0146$ ) but no significances were found in comparison between any other two groups (PSA-screened versus PSA screened with later diagnosis, $P=0.0811$; PSAscreened with later diagnosis versus clinically diagnosed,
$P=0.6425)$. On the contrary, there was no significance between PSA-screened and clinically diagnosed patients in $M$ staging subgroups (Figure 3c, $P=0.1763$ ).

Gleason score comparison was indicated in Figure $3 \mathrm{~d}$. There were $114(44.19 \%), 85$ (32.95\%) and 59 (22.87\%) patients in PSA screened patients; 22 (22.22\%), $28(28.28 \%)$ and $49(49.49 \%)$ in PSA screened with later diagnosis, and $70(25.55 \%), 62(22.63 \%)$ and 142 $(51.82 \%)$ in clinically diagnosed group with defined status 
Table 5: Clinical characteristics based on PSA-based mass screening and clinical diagnosis

\begin{tabular}{|c|c|c|c|c|c|c|c|c|c|}
\hline $\begin{array}{l}\text { Clinical } \\
\text { characteristics }\end{array}$ & $\begin{array}{l}\text { Whole } \\
\text { cohort } \\
\mathbf{N}>984\end{array}$ & & $\begin{array}{l}\text { PSA screened } \\
\quad \mathbf{N}>\mathbf{2 5 9}\end{array}$ & & $\begin{array}{c}\text { PSA screened } \\
\text { with later } \\
\text { diagnosis } N>99\end{array}$ & & $\begin{array}{c}\text { Clinically } \\
\text { diagnosed } \\
\mathrm{N}>617\end{array}$ & & Pvalue \\
\hline Median age, year & 71 & & 72 & & 74 & & 70 & & $P<0.0001$ \\
\hline \multicolumn{10}{|l|}{ Clinical staging } \\
\hline T staging* & & & & & & & & & $P<0.0001$ \\
\hline $\mathrm{T} 1$ & 53 & $5.4 \%$ & 18 & $6.9 \%$ & 4 & $4.0 \%$ & 31 & $5.0 \%$ & \\
\hline $\mathrm{T} 2$ & 382 & $38.8 \%$ & 229 & $88.4 \%$ & 76 & $76.8 \%$ & 77 & $12.3 \%$ & \\
\hline $\mathrm{T} 3$ & 118 & $12.0 \%$ & 6 & $2.3 \%$ & 12 & $12.1 \%$ & 100 & $16.0 \%$ & \\
\hline $\mathrm{T} 4$ & 181 & $18.4 \%$ & 5 & $1.9 \%$ & 7 & $7.1 \%$ & 169 & $27.0 \%$ & \\
\hline Missing data & 250 & $25.4 \%$ & 1 & $0.4 \%$ & 0 & $0.0 \%$ & 249 & $39.8 \%$ & \\
\hline N staging* & & & & & & & & & $\begin{array}{c}\text { N0 vs N1,2, } \\
P=0.0458\end{array}$ \\
\hline No & 517 & $52.5 \%$ & 140 & $54.1 \%$ & 19 & $19.2 \%$ & 358 & $57.2 \%$ & \\
\hline $\mathrm{N} 1,2$ & 29 & $2.9 \%$ & 2 & $0.8 \%$ & 2 & $2.0 \%$ & 25 & $4.0 \%$ & \\
\hline $\mathrm{Nx}$ & 438 & $44.5 \%$ & 117 & $45.2 \%$ & 78 & $78.8 \%$ & 243 & $38.8 \%$ & \\
\hline M staging* & & & & & & & & & $\begin{array}{l}\text { M0 vs M1, } \\
P<0.0001\end{array}$ \\
\hline M0 & 500 & $50.8 \%$ & 176 & $68.0 \%$ & 32 & $32.3 \%$ & 292 & $46.6 \%$ & \\
\hline M1 & 242 & $24.6 \%$ & 77 & $29.7 \%$ & 65 & $65.7 \%$ & 100 & $16.0 \%$ & \\
\hline Mx & 242 & $24.6 \%$ & 6 & $2.3 \%$ & 2 & $2.0 \%$ & 234 & $37.4 \%$ & \\
\hline $\begin{array}{c}\text { Median } \\
\text { PSA(IQR), ng/mL }\end{array}$ & 28 & $\begin{array}{c}(0- \\
1000)\end{array}$ & 20 & $\begin{array}{c}(0.22- \\
124)\end{array}$ & 68 & $(5.1-150)$ & 38 & $(0-1000)$ & $P<0.0001$ \\
\hline Missing data & 347 & $35.3 \%$ & 0 & $0.0 \%$ & 0 & $0.0 \%$ & 347 & $56.2 \%$ & \\
\hline Gleason score & & & & & & & & & $P<0.0001$ \\
\hline$<=6$ & 206 & $20.9 \%$ & 114 & $44.0 \%$ & 22 & $22.2 \%$ & 70 & $11.2 \%$ & \\
\hline 7 & 175 & $17.8 \%$ & 85 & $32.8 \%$ & 28 & $28.3 \%$ & 62 & $9.9 \%$ & \\
\hline 8 & 115 & $11.7 \%$ & 31 & $12.0 \%$ & 30 & $30.3 \%$ & 54 & $8.6 \%$ & \\
\hline 9 & 111 & $11.3 \%$ & 26 & $10.0 \%$ & 18 & $18.2 \%$ & 67 & $10.7 \%$ & \\
\hline 10 & 24 & $2.4 \%$ & 2 & $0.8 \%$ & 1 & $1.0 \%$ & 21 & $3.4 \%$ & \\
\hline Missing data & 353 & $35.9 \%$ & 1 & $0.4 \%$ & 0 & $0.0 \%$ & 352 & $56.2 \%$ & \\
\hline $\begin{array}{l}\text { Management } \\
\text { approach }\end{array}$ & & & & & & & & & $P=0.0049$ \\
\hline Curative & 53 & $5.4 \%$ & 24 & $9.3 \%$ & 5 & $5.1 \%$ & 24 & $3.8 \%$ & \\
\hline Non-curative & 931 & $94.6 \%$ & 235 & $90.7 \%$ & 94 & $94.9 \%$ & 602 & $96.2 \%$ & \\
\hline $\begin{array}{l}\text { No. of all-cause } \\
\text { death, no. }(\%)\end{array}$ & 261 & $26.5 \%$ & 60 & $23.2 \%$ & 40 & $40.4 \%$ & 161 & $25.7 \%$ & \\
\hline $\begin{array}{l}\text { No. of prostate } \\
\text { cancer specific } \\
\text { death, no. }(\%)\end{array}$ & 217 & $22.1 \%$ & 30 & $11.6 \%$ & 37 & $37.4 \%$ & 150 & $24.0 \%$ & \\
\hline $\begin{array}{l}\text { Median follow-up } \\
\text { time, year }\end{array}$ & 5 & $\begin{array}{c}(0.08- \\
23)\end{array}$ & 7 & $(1-16)$ & 5 & $(1-11)$ & 4 & $(0.08-23)$ & $P<0.0001$ \\
\hline
\end{tabular}

IQR, interquartile range; *Percentages may not add up to 100 due to rounding. 
stratified in the subgroups of Gleason $\leq 6$, Gleason 7 and Gleason $\geq 8$, respectively. Significant differences were found in the groups of PSA-screened versus PSA-screened with later diagnosis and PSA-screened versus clinically diagnosed group $(P<0.0001)$, whereas there was no significance in PSA-screened patients with later diagnosis compared with those diagnosed clinically $(P=0.5048)$.

As to management approach (Figure 3e), a statistically significant difference was found between the PSA- screened and clinically diagnosed groups $(P=0.0018)$, while no significant differences were found between any of other two groups (PSA-screened versus PSA-screened with later diagnosis, $P=0.5786$; PSA-screened with later diagnosis versus clinically diagnosed, $P=0.2780$ ).

(ii) Overall and prostate cancer-specific survivals

Since the purpose of PSA-based mass screening was to detect prostate cancer patients at an early stage in order to reduce mortality, survival was a very important factor in the evaluation of the effect of PSA mass screening. Therefore, Kaplan-Meier plots were compared among PSA-screened, PSA-screened with later diagnosis, and the clinically diagnosed groups in our study.
For overall survivals, five-year survivals were $87.66 \%, 69.19 \%$ and $74.46 \%$, respectively, and $10-$ year survivals were $68.50 \%, 39.05 \%$ and $64.16 \%$, respectively in PSA-screened, PSA-screened with later diagnosis and clinically diagnosed groups (Figure 4a, $P<0.0001)$. There were also statistically significant differences between any of the two groups, including patients from PSA-screened versus clinically diagnosed (Figure 4c, $P=0.0054$ ), PSA-screened versus PSAscreened with later diagnosis (Figure 4e, $P<0.0001$ ) and PSA-screened with later diagnosis versus clinically diagnosed (Figure 4g, $P=0.0199$ ).

Prostate cancer-specific five-year survivals were $90.92 \%, 69.19 \%$ and $76.31 \%$, respectively, and $10-$ year survivals were $82.72 \%, 41.74 \%$ and $65.76 \%$, respectively in the PSA-screened, PSA-screened with later diagnosis, and clinically diagnosed groups (Figure $4 \mathrm{~b}, P<0.0001)$. Statistically significant differences were found when comparing PSA-screened with clinically diagnosed (Figure 4d, $P<0.0001$ ), PSA-screened versus PSA-screened with later diagnosis (Figure 4f, $P<0.0001$ ) and PSA-screened with later diagnosis versus clinically diagnosed groups (Figure 4h, $P<0.0278$ ).
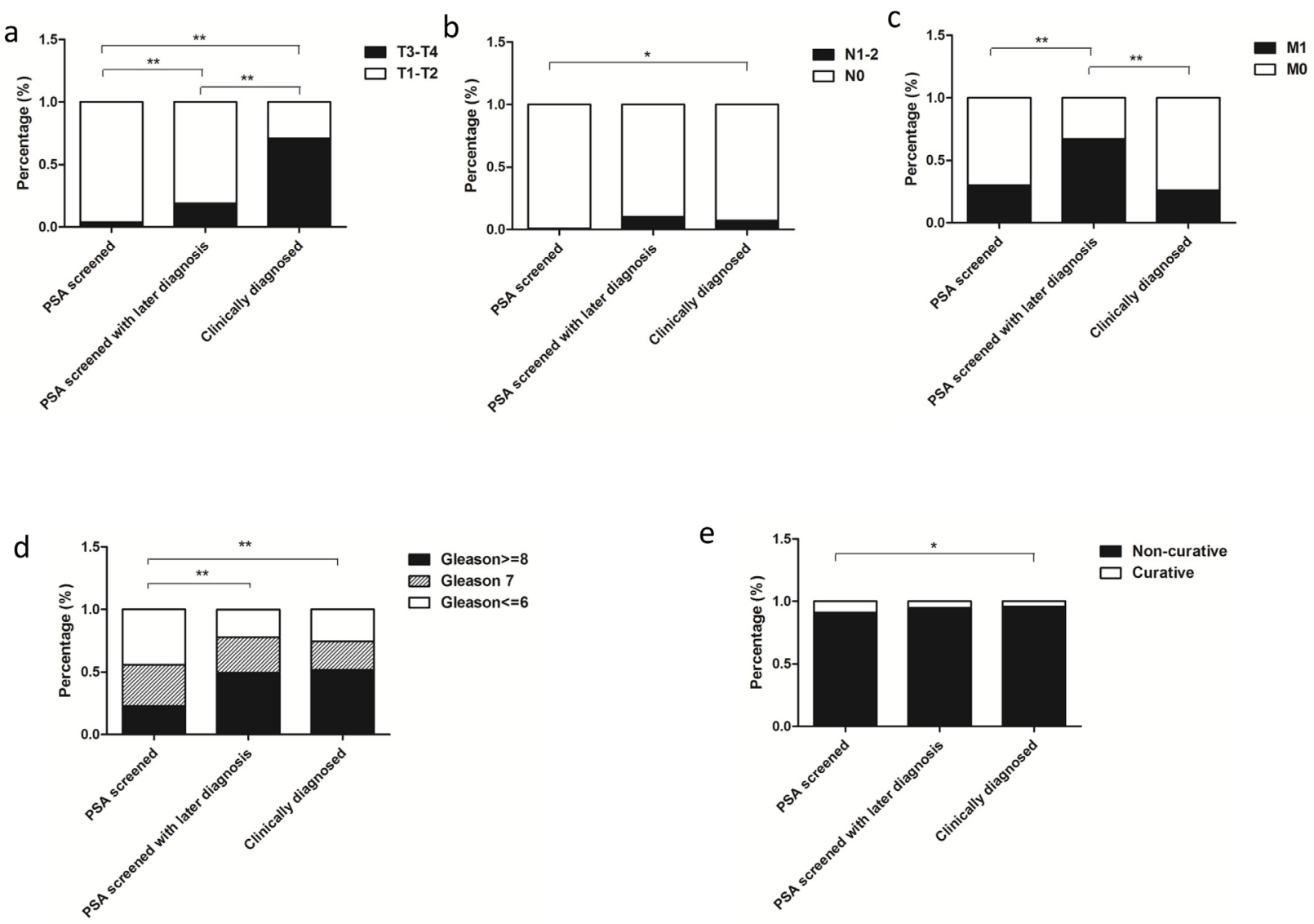

Figure 3: Clinical characteristics and survivals in PSA screened, PSA screened with later diagnosis and clinically diagnosed prostatic adenocarcinoma patients. (a) $\mathrm{T}$ staging distribution. (b) Distribution of $\mathrm{N}$ staging. (c) Distribution of $\mathrm{M}$ staging. (d) Gleason score distribution. (e) Management approach comparison among three subcategories $(P<0.0001)$. ${ }^{*} P<0.05 ; * * P<0.01$. 


\section{DISCUSSION}

To the best of our knowledge, this study done between 1996 and 2012 by the Center of Diagnosis, Treatment and Research of Prostate Disease of Jilin University and JICA is the first PSA-based mass screening project in China. Our study is also the first in China to compare the clinical and survival characteristics of prostate cancer patients diagnosed through PSA mass screening with those of clinically diagnosed patients.

Prostate cancer is one of the most common malignancies among males [1]. PSA-based mass screening has been widely used in the United States since the late 1980s. Although it caused a dramatic increase in the detection of prostate cancer in late 1980s and early $1990 \mathrm{~s}$, it is presumed to be responsible for the lowered mortality reported both in the United States and European countries $[2,3]$. In the United States, the five-year survival was reported over $97 \%$ from 2006 to 2012 for all stages of prostate cancer [7] and an European randomized study showed a more than $90 \%$ prostate cancer-specific survival after a median follow-up of around 13 years [10]. However, in our study, the five-year and 10-year survival rates in a Chinese cohort were much lower, at $77.52 \%$ and $62.57 \%$, respectively for overall survival and $79.65 \%$ and $68.60 \%$, respectively, for prostate cancer-specific survival. This discrepancy possibly can be explained by decades-long routine usage of PSA-based mass screening in Western countries. Early-stage diagnosis of prostate cancer generally enabled many different treatment options, including curative management, to be possible [17, 22].

PSA level, T staging and Gleason score are still the three important diagnostic markers and outcome predictors [11]. As expected in our study, we found that a

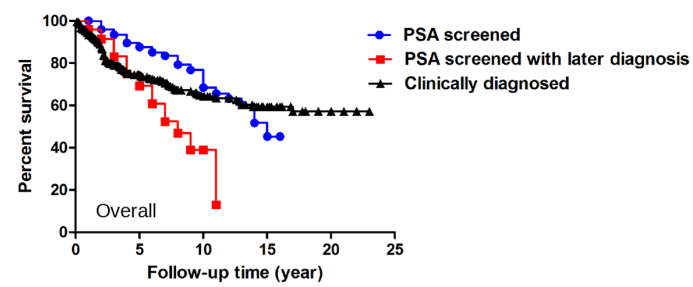

C

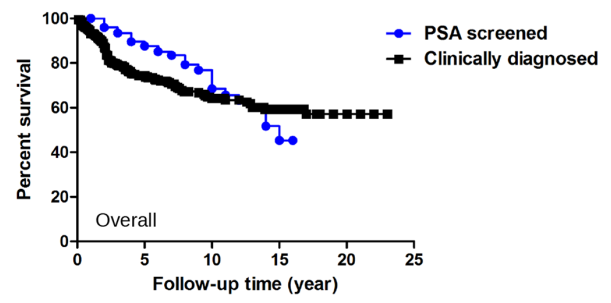

e

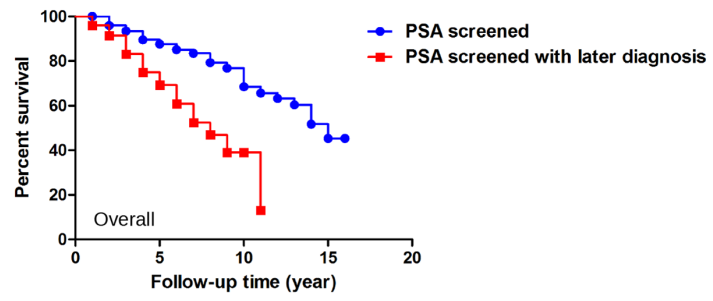

g

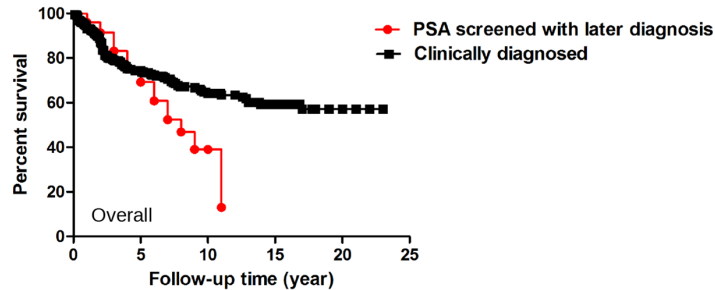

b

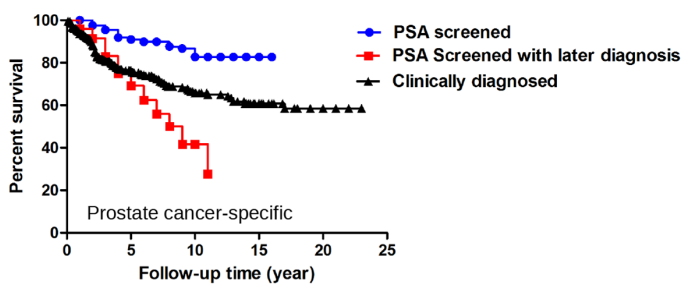

d

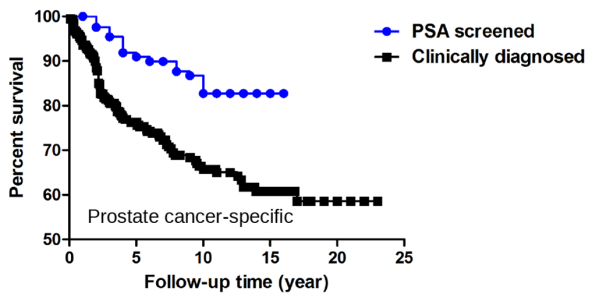

$f$

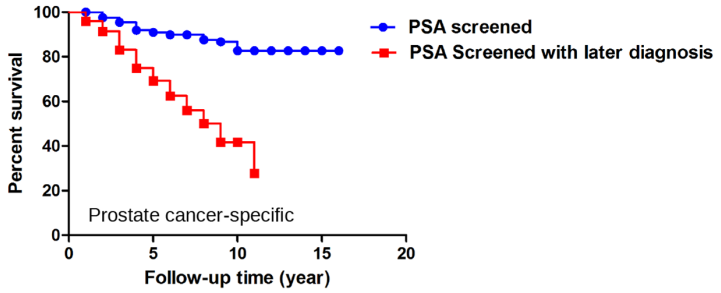

$\mathrm{h}$

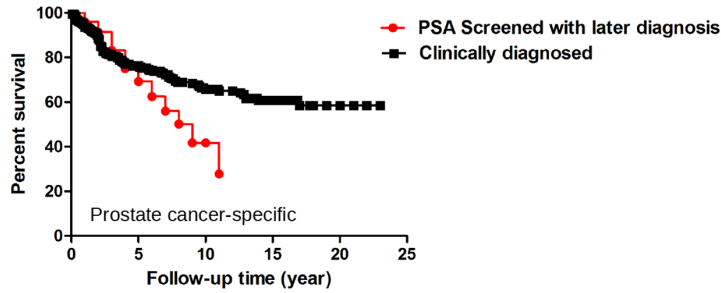

Figure 4: Overall and prostate cancer-specific survival comparison among PSA screened, PSA screened with later diagnosis and clinically diagnosed patients. $(\mathbf{a}, \mathbf{b})$ Overall and prostate cancer-specific survival comparison among PSA screened, PSA screened with later diagnosis and clinically diagnosed patients. (c, d) Overall and prostate cancer-specific survival comparison between PSA screened and clinical diagnosed patients. (e, f) Overall and prostate cancer-specific survival comparison between PSA screened patients and PSA screened with later diagnosis. (g, h) Overall and prostate cancer-specific survival comparison between PSA screened with later diagnosed and clinically diagnosed patients. 
men with metastases had a significantly high PSA level and significant differences in $\mathrm{T}$ staging and Gleason score. Prostate cancer can be stratified into different risk groups based on metastatic status and management approach and men free from metastases or treated by radical prostatectomy had better prognosis with significantly longer survival time. Moreover, as a highly heterogeneous disease with respect to survival time and disease recurrence, prostate cancer was subdivided into different risk groups for better management selection. The NCCN classification, as one of the stratification systems, categorizes prostate cancer into low, intermediate and high risk [11]. Our study showed that prostate cancer can be stratified into different risk groups based on the predictors Gleason score and $\mathrm{T}$ staging of the NCCN classification and T staging was further confirmed as a significant prognostic predictor by COX Proportional Hazard model. However, as a long-term retrospective study, the PSA, T staging and Gleason score information of a small portion of patients diagnosed in 1980s and early 1990s was incomplete or uncertain and may have had some influence on the survival comparison based on NCCN classification. Hence, more studies need to be done before the NCCN classification can be used for the life expectancy evaluation in prostatic adenocarcinoma patients in China.

In the past decade, PSA-based mass screening has become controversial owing to the uncertain balance between the benefits of screening and the harmful effects of overdiagnosis and overtreatment $[12,13]$. In 2013, Ilic D et al. reviewed 5 randomized controlled trials (RCTs) with a total of more than 340,000 men who had had PSA-based screening and found no statistically significance in prostate cancer-specific mortality between the screened and control groups [14]. Of the five RCTs, 2 done by the European Randomized Study of Screening for Prostate Cancer (ERSPC) and the US Prostate, Lung, Colorectal and Ovarian (PLCO) Cancer Screening Trial were indicated to have a low risk of bias but presented contradictory results [14]. The former reported a significant reduction in prostate cancer-specific mortality attributable to screening at 9,11 and 13 years of followup, while the latter showed no significance [4, 15-17]. In our study, PSA-based mass screening detected 358 cases of prostatic adenocarcinoma, including 259 immediate and 99 later diagnoses. Consistently, we found more early-stage prostate cancer in PSA-screened patients, with a significantly higher percentage in T1-2, N0 and Gleason $\leq 6$ subgroups, compared with patients who had had PSA screening with later diagnosis or a clinical diagnosis. The results resemble the situation in Western countries at a time when PSA-based mass screening was not used routinely $[18,19]$ which indicated that PSAbased mass screening was able to detect most still organ- confined and potentially curable prostate cancer patients and to improve survival. Our data are also supported by a report from the United States that following a 2012 USPSTF recommendation that discouraged routine PSA screening, there was a decrease in the detection of prostate cancer at an early stage. Another study concluded that the USPSTF recommendation was followed by an increase in metastatic prostate cancer $[7,10]$. A retrospective multicenter study documented a high incidence of advanced prostate cancer in a Chinese cohort due to the absence of PSA-based mass screening [20]. More importantly, we found that overall and prostate cancer-specific survival rates were significantly higher in PSA-screened patients than in the PSA-screened patients with later diagnosis and the clinically diagnosed patients. Statistically significant differences were found when any two of the three groups were compared.

PSA-based mass screening has not been widely used in China yet but has been in routine use in the United States and European countries for decades. As a result, by the time a diagnosis of prostate cancer is made in China, the disease is much more advanced, resulting in a higher death rate $[8,9,11]$. Considering its small sample size and the short length of follow-up, our study may not fully reflect the effect of PSA-based mass screening on the Chinese cohort, so this study alone may not be sufficient to justify a recommendation for the routine use of PSA-based screening in China. However, based on the results of our study and the long-term trends and proven benefits of mass screening in the Western countries, we suggest that at least one nation-wide PSA-based mass screening at age $>50$ could be done in China to identify the potentially large number of asymptomatic patients and to reduce mortality caused by advanced prostate cancer and associated health care costs $[21,22]$. In addition, considering the inequality of medical health resource allocation in China, there could be an opportunity for primary care physicians to gain awareness and training in PSA-based screening, especially in less developed areas.

In summary, we report here that a Chinese cohort has lower overall and prostate cancer survival rates than it is reported in western countries. The metastatic status, management approach, and $\mathrm{T}$ staging and Gleason score of the NCCN classification are significant predictors of both overall and prostate cancer-specific survivals. Most importantly, the incidence of early-stage prostate cancer found in PSA-based mass screening was high and PSAscreened patients had both a prolonged overall and prostate cancer-specific survival in comparison to clinically diagnosed patients. Our study suggests that at least one nation-wide PSA-based mass screening at age $>50$ could be done in China to identify the potentially large number of asymptomatic patients and to reduce mortality caused by advanced prostate cancer and associated health care costs. 


\section{MATERIALS AND METHODS}

\section{Study cohort}

The study cohort consisted of 1,012 prostate cancer patients diagnosed between August, 1980 and April, 2012. Of these patients, 383 were detected by the PSAbased mass screening program done by the Center of Diagnosis, Treatment and Research of Prostate Disease of Jilin University between 1996 and 2012, with either immediate or later diagnosis. Other data used for this retrospective study were collected from prostate cancer patients diagnosed and treated in any of the three affiliated hospitals of Jilin University (The First Hospital of Jilin University, The Second Hospital of Jilin University and the China-Japan Union Hospital of Jilin University), Changchun (Changchun, China).

A total of 19,808 men aged over 50 years old from six major companies and institutions in the urban area of Changchun were interviewed and screened for prostate cancer based on total serum PSA level determination using the Elisa assay kit (CanAGDiagnostics, Gothenburg, Sweden). Men with PSA levels $>4.0 \mathrm{ng} / \mathrm{mL}$ and those with obstructive symptoms (irrespective of PSA levels) were recommended for transrectal ultrasound-guided systematic sextant biopsies and subsequent pathological analysis. Among these patients, 259 men agreed to biopsies and were diagnosed as having prostatic adenocarcinoma immediately (hereafter referred to as PSA screened patients). However, another 99 men refused the biopsies for final diagnosis at the first time although their PSA levels $>4.0 \mathrm{ng} / \mathrm{mL}$ and were diagnosed as prostatic adenocarcinoma in later years when their PSA level climbed further to a very high level (hereafter referred to as PSA screened patients with later diagnosis).

Basic patient characteristics of patients were evaluated and recorded by physicians: year of diagnosis, age, PSA, management approach, clinical staging (Tumor Node Metastasis, TNM), Gleason score at the time of diagnosis and survival time when applicable. Sextant biopsies were performed by pathologists with expertise in genitourinary tumors for Gleason score determination. Curative management was defined as radical prostatectomy only in this study. Metastatic prostate cancers were defined as the patients with distant or nodal metastasis at the time of diagnosis. Follow-up began after treatment and the cut-off date for death determination was 15 August, 2016. Survival time was defined as duration from the date of diagnosis to deceased date or census date.

Clinical characteristics of the study cohorts stratified by age or metastatic status at diagnosis were investigated. Then both overall and prostate cancer-specific survival was compared for prostatic adenocarcinoma of PSA screened and clinically diagnosed patients based on clinical characteristics and the National Comprehensive Cancer
Network (NCCN) risk classification. Cox Proportional Hazards Model analysis was done for prostatic carcinoma patients for risk predictors identification. Furthermore, clinical characteristics and survival were further compared among PSA screened, PSA screened with later diagnosis and clinically diagnosed prostatic adenocarcinoma patients to evaluate the effect of PSA-based mass screening in China.

\section{Statistical analysis}

Distribution of categorical clinical characteristics, including TNM staging, Gleason score, management approach and year of diagnosis, were compared using the Pearson Chi-Square test. Mann-Whitney test was used to compare PSA level, age at the time of diagnosis and follow-up time since the data were not in a standard normal distribution. The log-rank test was used to analyze the distribution of survival time. COX proportional hazard model was applied to identify significant predictors using a backward variable selection method with an elimination criterion of 0.05 , and parameters included for analysis were age at diagnosis, year of diagnosis, PSA levels, Gleason score, clinical staging and management approach. Results were considered statistically significant when $P<0.05$.

\section{Author contributions}

Libo Xu, Ling Zhang and Xuejian Zhao conceived and designed the experiments; Haixia Zhang performed statistical analysis; Jinguo Wang, Baofeng Guo, Kaichen Wang, Ding Wang and Chang Dai collected the data; Libo $\mathrm{Xu}$ wrote the manuscript. All the authors contributed to the review of the manuscript.

\section{ACKNOWLEDGMENTS}

The study is funded by the China Scholarship Council (CSC) (No. 201606170233), the National Natural Science Foundation of China (No. 81201188 and No. 81472344) and Research Fund for the Scientific and the International Cooperation Project of Jilin Provincial Science and Technology Department (No. 20150414031GH) and the Education Department of Jilin Province, "13th Five-Year" science and technology research (grant no. [2016] 455). Also we thank Lesley Inglis and John Inglis, Cold Spring Harbor Laboratory for language editing.

\section{CONFLICTS OF INTEREST}

The authors have no conflicts of interest to declare regarding the manuscript. 


\section{REFERENCES}

1. Fitzmaurice C, Dicker D, Pain A, Hamavid H, MoradiLakeh M, MacIntyre MF, Allen C, Hansen G, Woodbrook R, Wolfe C, Hamadeh RR, Moore A, Werdecker A, et al. The global burden of cancer 2013. JAMA Oncol. 2015; 1: 505-27. https://doi.org/10.1001/jamaoncol.2015.0735.

2. Hoffman RM, Meisner AL, Arap W, Barry M, Shah SK, Zeliadt SB, Wiggins CL. Trends in United States prostate cancer incidence rates by ge and stage, 1995-2012. Cancer Epidemiol Biomarkers Prev. 2016; 25: 259-63. https://doi. org/10.1158/1055-9965.EPI-15-0723.

3. http://uroweb.org/guideline/prostate-cancer/\#5.

4. Schröder FH, Hugosson J, Roobol MJ, Tammela TL, Zappa M, Nelen V, Kwiatkowski M, Lujan M, Määttänen L, Lilja H, Denis LJ, Recker F, Paez A, et al. Screening and prostate cancer mortality: results of the European Randomised Study of Screening for Prostate Cancer (ERSPC) at 13 years of follow-up. Lancet. 2014; 384: 2027-35. https://doi. org/10.1016/s0140-6736(14)60525-0.

5. Deng J, Gao JT, Xie T. Clinical epidemiological study on prostate cancer. Tumor. 1995; 15: 340-3.

6. Jemal A, Fedewa SA, Ma J, Siegel R, Lin CC, Brawley $\mathrm{O}$, Ward EM. Prostate cancer incidence and PSA testing patterns in relation to USPSTF screening recommendations. JAMA. 2015; 314: 2054-61. https://doi.org/10.1001/ jama.2015.14905.

7. Siegel RL, Miller KD, Jemal A. Cancer Statistics, 2017. CA Cancer J Clin. 2017; 67: 7-30. https://doi.org/10.3322/ caac. 21387.

8. U.S. Preventive Services Task Force. Screening for prostate cancer: US Preventive Services Task Force recommendation statement. Ann Intern Med. 2008; 149: 185-91.

9. Moyer VA; U.S. Preventive Services Task Force. Screening for prostate cancer: U.S. Preventive Services Task Force recommendation statement. Ann Intern Med. 2012; 157: 120-34.

10. Roobol MJ, Kranse R, Bangma $\mathrm{CH}$, van Leenders AG, Blijenberg BG, van Schaik RH, Kirkels WJ, Otto SJ, van der Kwast TH, de Koning HJ, Schröder FH; ERSPC Rotterdam Study Group. Screening for prostate cancer: results of the Rotterdam section of the European randomized study of screening for prostate cancer. Eur Urol. 2013; 64: 530-9. https://doi.org/10.1016/j.eururo.2013.05.030.

11. Mohler JL, Armstrong AJ, Bahnson RR, D'Amico AV, Davis BJ, Eastham JA, Enke CA, Farrington TA, Higano CS, Horwitz EM, Hurwitz M, Kane CJ, Kawachi MH, et al. Prostate Cancer, Version 1.2016. J Natl Compr Canc Netw. 2016; 14: 19-30.
12. Roobol MJ, Bokhorst LP. The ProtecT trial: what can we expect? Lancet Oncol. 2014; 15: 1046-7. https://doi. org/10.1016/S1470-2045(14)70198-6.

13. Loeb S, Bjurlin M, Nicholson J, Tammela TL, Penson DF, Carter HB, Carroll P, Etzioni R. Overdiagnosis and overtreatment of prostate cancer. Eur Urol. 2014; 65: 104655. https://doi.org/10.1016/j.eururo.2013.12.062.

14. Ilic D, Neuberger MM, Djulbegovic M, Dahm P. Screening for prostate cancer. Cochrane Database Syst Rev. 2013: CD004720. https://doi.org/10.1002/14651858.CD004720. pub3.

15. Andriole GL, Crawford ED, Grubb RL 3rd, Buys SS, Chia D, Church TR, Fouad MN, Isaacs C, Kvale PA, Reding DJ, Weissfeld JL, Yokochi LA, O'Brien B, et al. Prostate cancer screening in the randomized Prostate, Lung, Colorectal, and Ovarian Cancer Screening Trial: mortality results after 13 years of follow-up. J Natl Cancer Inst. 2012; 104: 125-32. https://doi.org/10.1093/jnci/djr500.

16. Schröder FH, Hugosson J, Roobol MJ, Tammela TL, Ciatto S, Nelen V, Kwiatkowski M, Lujan M, Lilja H, Zappa M, Denis LJ, Recker F, Páez A, et al. Prostate-cancer mortality at 11 years of follow-up. N Engl J Med. 2012; 366: 981-90. https://doi.org/10.1056/NEJMoa1113135.

17. Schröder FH, Hugosson J, Roobol MJ, Tammela TL, Ciatto S, Nelen V, Kwiatkowski M, Lujan M, Lilja H, Zappa M, Denis LJ, Recker F, Berenguer A, et al. Screening and prostate-cancer mortality in a randomized European Study. N Engl J Med. 2009; 360: 1320-8. https://doi.org/10.1056/ NEJMoa0810084.

18. Catalona WJ, Smith DS, Ratliff TL, Basler JW. Detection of organ-confined prostate cancer is increased through prostate-specific antigen-based screening. JAMA. 1993; 270: 948-54.

19. Kabalin JN. Screening for prostate cancer today. West J Med. 1995; 162: 272-3.

20. Peyromaure M, Debre B, Mao K, Zhang G, Wang Y, Sun $\mathrm{Z}, \mathrm{Xu} \mathrm{D}$, Jiang J, Sun Y. Management of prostate cancer in China: a multicenter report of 6 institutions. J Urol. 2005; 174: 1794-7. https://doi.org/10.1097/01. ju.0000176817.46279.93.

21. Popiolek M, Rider JR, Andrén O, Andersson SO, Holmberg L, Adami HO, Johansson JE. Natural history of early, localized prostate cancer: a final report from three decades of follow-up. Eur Urol. 2013; 63: 8.

22. Vickers AJ, Ulmert D, Sjoberg DD, Bennette CJ, Björk T, Gerdtsson A, Manjer J, Nilsson PM, Dahlin A, Bjartell A, Scardino PT, Lilja H. Strategy for detection of prostate cancer based on relation between prostate specific antigen at age 40-55 and long term risk of metastasis: case-control study. BMJ. 2013; 346: f2023. 